\title{
Os Idosos e a Vivência do Tempo: Implicações nos Processos de Desenvolvimento
}

\section{Older Adults and their Time Experiences: Implications in}

Development Processes

Os Idosos e a Vivência do Tempo

\section{Older Adults and their Time Experiences}

\author{
Gilberto Lima dos Santos 1
}

\begin{abstract}
Resumo
O objetivo do presente estudo consistiu em compreender como os idosos vivenciam o tempo e suas possíveis implicações nos processos de desenvolvimento, diante da suposta proximidade da morte. Trata-se de uma pesquisa qualitativa, orientada por uma perspectiva cultural e narrativista, no campo da Psicologia. Os participantes foram oito idosos membros de uma Associação de Bairro. As narrativas foram produzidas por meio da realização de entrevistas individuais semiestruturadas e de grupo focal. A análise foi baseada na compreensão das narrativas dos participantes e na apreensão dos significados constituídos. Os resultados foram organizados em categorias previamente definidas, de acordo com os objetivos específicos, e em categorias emergentes, ao longo de um movimento dialógico entre as dimensões empírica e teórica. Os participantes vivenciam as dimensões do tempo de modos peculiares, e essas vivências repercutem na forma como se posicionam em relação à vida e à morte e vice-versa.
\end{abstract}

Palavras-chave: Idosos. Tempo. Narrativas. Significados. Desenvolvimento.

\begin{abstract}
The aim of this study was to understand how older adults experience their time and its possible implications in the processes of development, given the alleged proximity to death. It is a qualitative research, driven by a cultural and narrative perspective in the field of Psychology. The participants were eight older adults from a Neighborhood Association. The narratives were produced through individual semi-structured interviews and focus group. The analysis was based on the understanding of the participants' narratives and seizure of the meanings constituted. The results were organized into predefined categories, according to specific objectives, and on emerging categories over a dialogic movement between the empirical and theoretical dimensions. Participants experience the past, present and future of peculiar modes, and these experiences resonate in the way they take a stance on life and death and vice versa.
\end{abstract}

Keywords: Older adults. Time. Narratives. Meanings. Development.

${ }^{1}$ Universidade do Estado da Bahia, Senhor do Bonfim, Brasil. E-mail: glsantos@uneb.br 
As teorias clássicas do desenvolvimento psicológico priorizam, ou enfatizam, ordinariamente, os processos que transcorrem entre a infância e a adolescência. Frequentemente, isso ocorre em função do pressuposto de que, até o fim da adolescência, as características da idade adulta já se apresentam em suas configurações básicas. Isso significa que não há mais previsão de mudanças qualitativas radicais como aquelas ocorridas entre a infância e a adolescência. A partir daí, presume-se que as experiências contribuirão apenas para acentuar e atualizar essas características.

A Psicanálise pode ser considerada uma das mais importantes e antigas teorias de estágio. Ao descrever o desenvolvimento afetivo-sexual, o modelo original, concebido por Freud (1905/1973a; 1916-7/1973b), aponta quatro momentos diferenciados. No último estágio, que coincide com a adolescência, o indivíduo torna-se genitalmente adulto, ou seja, atinge o nível mais elevado do seu desenvolvimento.

Outra teoria destacou-se de modo especial no estudo do desenvolvimento cognitivo. Foi elaborada por Piaget (1999). Os estágios piagetianos mostram as transformações pelas quais a inteligência da criança passa, até que ela avance pela adolescência, que é quando alcança o cume do desenvolvimento e consegue pensar de forma lógica e abstrata.

Talvez Erikson (1998) tenha sido um dos poucos estudiosos do desenvolvimento, dentre os clássicos, a focalizar o envelhecimento como uma etapa cujas peculiaridades são merecedoras de atenção. Para ele, o desenvolvimento psicossocial é constituído por uma sucessão de oito estágios críticos. Cada um desses estágios é marcado por tensões, conflitos, com duas saídas alternativas.
No último estágio, concernente à velhice, o conflito pode encaminhar para a integridade ou o desespero e o desgosto. Se o indivíduo é capaz de rever sua vida de modo positivo, sem sentimentos de culpa, arrependimentos ou mágoas, tende a sentir-se íntegro, esperançoso e tranquilo. Do contrário, vivencia o desespero e o desgosto.

Neste ponto, torna-se crucial, para esta discussão, evocar a teorização de Vygotsky (1984/2000). O que nos interessa, especialmente, é que Vygotsky (1984/2000) adota uma posição bastante diferenciada - em relação aos autores citados anteriormente - quanto à forma pela qual se chega à idade adulta. Primeiro, devemos destacar que, para ele (1984/2000), o ápice do desenvolvimento individual coincide com a aquisição dos padrões comportamentais adultos. Situa-se, portanto, para além da adolescência. Ademais, em sua concepção, os padrões comportamentais adultos não são universais, mas culturais. Por conseguinte, podem ser muito diversos.

Entretanto, uma das contribuições mais importantes e originais que Vygotsky $(1984 / 2000)$ traz para o estudo do desenvolvimento humano é a sua afirmação de que os padrões comportamentais adultos atuam, ao longo de todo esse processo, como padrões a serem internalizados pelo indivíduo. Os estágios precedentes funcionam como aproximações a esses padrões. Enquanto modelos socialmente desejáveis, a aquisição desses padrões supõe um empenho intencional por parte do indivíduo em desenvolvimento e, também, por parte daqueles que se ocupam com sua educação. Portanto, esses padrões influenciam todo o desenvolvimento. Consequentemente, não se chega a esses padrões 
adultos naturalmente. Chega-se intencional e culturalmente.

Convém salientar que a capacidade interpretativa e as vivências individuais são fundamentais no processo de apropriação de modelos e padrões socialmente disponíveis, de acordo com a concepção de Vygotsky (1984/2000). Sendo assim, podemos compreender que esses padrões de atuação adultos ensejam e orientam a reprodução e a manutenção do que é comum, compartilhado, em determinada cultura ou coletividade, e, ao mesmo tempo, possibilitam a construção das singularidades e, consequentemente, a complexificação da diversidade. Isto é, esses modelos não são simplesmente copiados, mas transformados em versões individuais.

Concordamos com Vygotsky (1984/2000), quanto ao papel que os padrões ou modelos adultos exercem em relação às etapas anteriores. Afinal, o mundo adulto se impõe à criança desde o seu nascimento. Podemos compreender, por conseguinte, que padrões e valores adultos sejam socialmente privilegiados em contextos culturais que se pautem pela lógica da produtividade, em contextos culturais nos quais a educação das crianças é conduzida, prioritariamente, por seus pais e professores etc. Parece-nos razoável, entretanto, o entendimento de que, em contextos socioculturais pautados por lógicas diferenciadas, os modelos adultos podem ceder lugar a modelos de outras fases do desenvolvimento.

Tradicionalmente, de acordo com Camarano, Mello e Kanso (2006), são três as fases da vida: infância e adolescência constituem a primeira, a vida adulta é a segunda e a velhice a terceira; mas, atualmente, são apontadas sete fases: infância, adolescência, juventude, idade adulta ou madura, meia idade, terceira e quarta idades. O Estatuto da Criança e do Adolescente (Brasil, 1995) relaciona a infância à etapa que vai de zero a 12 anos incompletos, e a adolescência à faixa etária que vai dos 12 aos 18 anos. Porém, nas últimas décadas, segundo Traverso-Yépez e Pinheiro (2002), a Organização Mundial da Saúde (OMS) tem usado o termo juventude para se referir à faixa etária entre 15 e 24 anos, em função do alongamento dessa fase.

Ribeiro (2004) chama a atenção para a quebra, na atualidade, da linearidade da vida construída na modernidade. Para ele, a sequência que parte da infância, passa pela juventude, pela idade adulta e pela maturidade; para chegar à velhice, assume hoje novas configurações: “Ora, essas posições deixam de estar equacionadas ao longo de uma sequência sem volta. Continuam tendo sentido, mas não mais como datas, e sim como posições, que podemos saltar, repetir ou reciclar” (p. 27). Madeira (2006) também toca esse ponto e situa nos anos 1970 o momento até quando predominou essa previsibilidade garantida pela compreensão sequencial dos estágios da vida. Segundo essa autora, foi a partir dos anos 1980 que as fronteiras entre os estágios começaram a perder a nitidez, ao mesmo tempo em que os comportamentos não convencionais tornaram-se cada vez mais socialmente aceitáveis.

A percepção dessas possibilidades permite a compreensão da emergência da juventude como ideal social, como o próprio Ribeiro (2004, p. 26) põe em pauta.

[...] a juventude atualmente constitui um certo ideal social, que talvez jamais termine. A ideia de liberdade pessoal, em 
nossa sociedade, está cada vez mais marcada por valores que associamos à mocidade. O corpo bem cuidado, a saúde, a liberdade até mesmo de desfazer relacionamentos, a possibilidade de sucessivos recomeços afetivos e profissionais: tudo isso tem a ver com uma conversão do humano em jovem.

Para Kehl (2004), a eleição da juventude como ideal social é problemática para os próprios jovens, porque os deixa sem referências para pensar sobre e se dirigir ao futuro. Com certo exagero, ela questiona: "Como ingressar no mundo adulto onde nenhum adulto quer viver? $\mathrm{O}$ que os espera, então?” (p. 97).

A insatisfação com o próprio corpo, caracterizada por Adami et al. (2008), e a correspondente busca do ideal de beleza dizem respeito ao recente prestígio adquirido pela juventude. Isso teria acontecido após a década de 1950, segundo Kehl (2004), quando o termo adolescência ganhou popularidade e "ser jovem virou slogan, virou clichê publicitário, virou imperativo categórico - condição para se pertencer a uma certa elite atualizada e vitoriosa" (p. 92). Antes disso, isto é, antes de ser catapultada pela indústria cultural à condição de modelo, a juventude vivia uma vida obscura, carregada de culpa e obediência, e moldada pelos discursos médicos e morais. Na primeira metade do século $\mathrm{XX}$, os homens eram mais valorizados ao ingressar no mundo do trabalho, na fase produtiva, e as mulheres eram mais valorizadas ao ingressar na fase reprodutiva.

A ascensão da juventude como ideal ocorreu na constituição de uma cultura cada vez mais marcada pela superficialidade, transitoriedade, fugacidade, pelo individualismo e pela valorização do novo e desqualificação e descarte do antigo. Em outros termos, a ascensão social da juventude (Ribeiro, 2004) significou, ao mesmo tempo, a indiferença e, frequentemente, o menosprezo pela velhice e pelo idoso.

$\mathrm{Na}$ contemporaneidade, a velhice tem sido concebida, predominantemente, como um período de decadência, constituído por desgastes, adoecimentos, perdas e limitações progressivas, como bem assinalam Schneider e Irigaray (2008) em sua revisão da literatura. Ou seja, desse ponto de vista menos atento à complexidade do desenvolvimento, esse período cessa na idade adulta e, a partir daí, somente degenera. Entretanto, a despeito dessa tendência homogeneizante, a diversidade se impõe. Dependendo do contexto sociocultural - como afirmamos anteriormente -, a velhice ainda pode ser a etapa mais valorizada da vida.

Podemos ver, por exemplo, com Benites (2014), a centralidade dos idosos na cultura Guarani e Kaiowá na atualidade. O referido autor salienta o papel das avós na educação das crianças, bem como a liderança dos idosos na condução dos assuntos importantes para essas comunidades indígenas. É aos idosos que os jovens recorrem na busca de soluções para seus dilemas sociais cotidianos, na certeza de que aí encontrarão o suporte da experiência e o apoio afetivo de que precisam.

Em outro exemplo, fornecido por Santos e Chaves (2007), encontramos a centralidade dos idosos na dinâmica social de uma comunidade quilombola. Nessa comunidade, os jovens ressaltam o conhecimento histórico dos mais velhos; conhecimento que propicia, aos jovens, suporte à elevação da autoestima e que lhes 
orienta no enfrentamento do preconceito com que se deparam no cotidiano em outros espaços sociais.

De todo modo, o que nos interessa, neste momento, é promover uma distinção de suma importância em nosso entendimento do desenvolvimento humano. $O$ fato de a idade adulta ser tomada como modelo para as etapas anteriores do desenvolvimento, ou de a juventude ser tomada como ideal para as etapas anteriores e posteriores, não faz de nenhuma delas, necessariamente, etapa final do desenvolvimento ou ponto culminante desse processo, pelo menos nos termos em que podemos compreender o desenvolvimento na atualidade.

Em nossa compreensão, a velhice não é apenas a etapa final do desenvolvimento ou do processo individual de humanização. A velhice é o seu ápice. Situar a velhice na curva descendente de uma parábola não parece mais representá-la adequadamente como em outras épocas. Nem mesmo numa visão restrita à dimensão biológica. Isso se torna cada vez mais patente à medida que a expectativa de vida das pessoas aumenta e que a quantidade de idosos aumenta em muitos países, a exemplo do Brasil. Nesse processo, tem-se evidenciado que os idosos vivenciam não apenas determinadas limitações previsíveis, mas, também, possibilidades não imaginadas até bem pouco tempo atrás.

Podemos dizer que as teorias dedicadas a descrever e compreender o desenvolvimento realizam, cada uma a seu modo, um relato das transformações pelas quais o indivíduo - como ser genérico - passa, do início ao fim da vida. Essas transformações são expressões do transcurso temporal, ou seja, desenvolvimento e temporalidade estão intimamente imbricados.
Entretanto, o transcurso temporal está implicado mais apropriadamente na perspectiva do observador, não reflete a perspectiva do sujeito em desenvolvimento. Por exemplo, na abordagem bioecológica de Bronfrenbrenner, segundo Martins e Szymanski (2004), o tempo aparece como categoria importante. Porém, diz respeito somente às transformações do indivíduo ao longo de determinados períodos e aos acontecimentos históricos de sua vida ou da vida de sua coletividade. Dito de outra forma, as teorias do desenvolvimento atentam, amiúde, para o tempo transcorrido, mas não para $\mathrm{o}$ “tempo vivido". Contudo, é justamente em relação ao tempo vivido que julgamos de fundamental importância a consideração da velhice como etapa final do desenvolvimento e como referência para a compreensão desse processo em sua totalidade.

Para Berger e Luckmann (2011), tempo e espaço são dimensões estruturantes do mundo da vida cotidiana. O tempo padrão da realidade diária é acessível no plano intersubjetivo e baseiase nas sequências de eventos da natureza e acrescentemos - nos marcadores culturais da vida coletiva. Sendo assim, essa temporalidade é inerente à consciência, quer dizer, todo indivíduo vivencia o tempo como fluxo interior, tendo como base os ritmos fisiológicos do organismo.

Encontramos em Vygotsky (1984/2000) indicadores do início da vivência temporal da criança. É o surgimento da função planejadora da fala que possibilita à criança emancipar-se do seu ambiente concreto imediato. Ao planejar suas ações com o auxílio da fala, a criança se desprende do presente, dimensiona o tempo. Constitui, assim, uma temporalidade que flui a partir de um passado recente para um futuro que se abre como 
possibilidades. Habilita-se, desse modo, a envolver-se em operações temporalmente complexas, ou melhor, sua subjetividade passa por uma transformação radical. Com o concurso da memória, elementos do passado, do presente e do futuro são criativamente sintetizados.

Nessa perspectiva, o tempo subjetivo e o tempo da vida cotidiana, instituído, não são coincidentes, embora devam ser continuamente correlacionados, isto é, o sujeito precisa ajustar seus projetos à estrutura temporal da vida cotidiana. Esse tempo convencional, embora seja contínuo e finito, é anterior ao nascimento do indivíduo e prossegue para além de sua morte. É o conhecimento da inevitabilidade da própria morte que impõe a finitude do tempo para o sujeito. $\mathrm{O}$ conhecimento de que dispõe de um tempo limitado para a realização de seus projetos afeta sua atitude quanto a essa realização. Por conseguinte, essa finitude do tempo gera uma espera ansiosa (Berger \& Luckmann, 2011).

Para Russell (2011), quando obtêm a aposentadoria e se livram das pressões do mundo do trabalho, os idosos veem a oportunidade de incrementar o próprio desenvolvimento, com foco no tempo e no significado. Ela entrevistou 16 adultos maiores de 70 anos para compreender suas experiências vividas como aprendizes de tecnologias da informação e comunicação. Dentre outras coisas, a citada autora notou que os idosos priorizam atividades que sejam mais significativas para eles. Não apenas escolhem muitas atividades para manterem-se ocupados. Mas, quando a atividade é significativa, não se importam se lhes toma todo o tempo do dia. Os idosos se atualizam em relação aos objetivos que viabilizam seu desenvolvimento no tempo de vida que lhes resta e olham para o futuro para além do tempo de sua própria vida. Em sua interpretação, a autora concluiu que o idoso planeja como se tivesse todo o tempo do mundo, mas vive o dia atual como se fosse o último.

Em outro estudo, Rendell et al. (2012) solicitaram que os participantes imaginassem os mesmos cenários com o intuito de comparar o pensamento episódico de dois grupos, um constituído por 24 adultos jovens (18 a 27 anos de idade) e outro formado por 25 idosos (65 a 82 anos de idade). Os autores concluíram que o desempenho dos idosos foi pior nos cenários futuros (comparado aos cenários atemporais). Essa diferença não houve entre os adultos jovens. Os idosos experienciam substancial dificuldade em imaginar vários tipos de cenários fictícios. Por meio de exames de ressonância magnética, os pesquisadores verificaram que havia comprometimento do hipocampo, isto é, seu funcionamento estava reduzido, afetando diretamente a evocação episódica dos idosos. Os autores argumentam que o hipocampo desempenha importante papel na coerência espacial, o que evidenciaria mais que a imaginação dos idosos pode ser fragmentada e apresentar lacunas. Em sua compreensão, as dificuldades dos idosos em imaginar um evento são ampliadas quando a consciência autonoética é requerida para projetar-se mentalmente no futuro.

Em síntese, o que encontramos na literatura são narrativas teóricas que focalizam o idoso de modos diversos, em termos de desenvolvimento, assim como o tempo implicado nesse processo. Estudos mais recentes, embora ainda relativamente escassos, passaram a evidenciar mais o envelhecimento como etapa da vida em que os processos de desenvolvimento seguem ativados, em vez de apenas declinarem 
rumo a um inevitável ocaso. Mais do que isso, esses estudos começaram a chamar a atenção para a importância de compreender como o tempo é vivido pelos idosos. É a partir daí que surgem as questões que norteiam o presente estudo: como os idosos vivenciam o tempo, diante da suposta iminência da morte? Se o futuro é, para a criança, abertura às possibilidades, o que é para o idoso? Como isso repercute em seus processos de desenvolvimento? Como o conhecimento acerca dessas questões pode contribuir para melhor compreender o desenvolvimento?

\section{Método}

Optamos por empreender uma investigação narrativa, pois, como De la Ossa e González (2013) afirmam, a narrativa focaliza especialmente a natureza temporal das experiências vitais. A narrativa organiza o tempo cronológico em ciclos, períodos, transições; e organiza tanto a memória quanto a perspectiva do porvir, ou seja, a vivência subjetiva do tempo, a percepção do passado, do presente e do futuro, o modo como se vive no tempo e o modo como se vive o tempo.

Entendemos a narrativa como modelo que as pessoas costumam utilizar para contar histórias. Portanto, a investigação narrativa estuda narrativas para compreender histórias e analisa histórias para obter narrativas (De la Ossa \& González, 2013). Dimensionamos isso mais adequadamente quando aprendemos com Bruner (2002, p. 100) que "[...] as pessoas transformam em narrativa sua experiência do mundo, assim como do papel que nele desempenham [...]".

Os modelos narrativos são fornecidos pela cultura e as histórias são construídas individual e coletivamente. É no bojo dessas histórias, como Bruner (2002) assinala, que encontramos os significados, e sem estes as interações sociais são simplesmente inviáveis. Segundo Vygotsky (1984/2000), os significados são conhecimentos comuns, compartilhados. São produzidos na dimensão coletiva e refletem suas histórias. Porém, essa produção ocorre no campo da intersubjetividade, enquanto a comunicação e o intercâmbio social se desenrolam e, assim, os significados expressam, também, as circunstâncias momentâneas da interação social, as motivações e intencionalidades, bem como as vivências individuais.

Sendo assim, o presente empreendimento investigativo ganhou o formato de estudo de caso e foi conduzido numa perspectiva qualitativa, constituindo-se como processo interpretativo. Como objetivo geral, definimos compreender como os idosos vivenciam o tempo e suas possíveis implicações nos processos de desenvolvimento diante da suposta proximidade da morte. Os objetivos específicos foram definidos conforme segue.

1. Caracterizar as vivências temporais dos idosos com relação às suas dimensões constitutivas: passado, presente e futuro.

2. Identificar os significados de morte nas expressões e vivências dos idosos.

3. Configurar os significados produzidos pelos idosos quanto à presumível aproximação da morte.

\section{Participantes}

No Brasil, o Estatuto do Idoso (Brasil, 2003) define como idosa a pessoa com idade igual ou superior a 60 anos. Contudo, visando manter coerência com a perspectiva investigativa 
assumida, optamos por formular um convite aberto a todos os membros de uma Associação de Bairro que se considerassem idosos. Essa associação foi escolhida pelo fato de congregar vários idosos. O convite foi aceito por oito pessoas, que se dispuseram a participar da pesquisa e assinaram o Termo de Consentimento Livre e Esclarecido. Apenas uma delas era do sexo masculino e, também, apenas uma delas tinha idade um pouco inferior a 60 anos. A faixa etária ficou entre 58 e 83 anos. Todas eram moradoras de um bairro periférico de uma cidade do interior do estado da Bahia.

\section{Instrumentos e Procedimentos}

Para a construção de narrativas, foram utilizados os seguintes instrumentos: a técnica do grupo focal e, em seguida, a técnica da entrevista individual semiestruturada. Os objetivos específicos foram utilizados como eixos temáticos para a manutenção do foco narrativo durante a aplicação dessas duas técnicas. Sendo assim, o grupo focal foi centrado na vivência da passagem do tempo, como lembrança e como projeto. Essa perspectiva foi mantida na entrevista, buscando-se a explicitação de mais minúcias. Essa busca foi orientada por três perguntas básicas: 1. Você pensa mais sobre o passado, o presente ou o futuro? 2. Ao pensar sobre o futuro, este tende a ser próximo ou distante? 3. O que você pensa sobre o fim do seu tempo?

A realização do grupo focal e das entrevistas individuais ocorreu nas dependências da referida Associação de Bairro, em horários definidos pelos próprios participantes. A duração média de cada sessão de entrevista foi de 30 minutos e a duração do grupo focal foi de 60 minutos. Todas as sessões foram gravadas em áudio e, depois, transcritas.

As transcrições foram lidas quantas vezes consideradas necessárias, até que o seu conteúdo se tornasse inteligível a ponto de ensejar categorizações. Foram utilizadas categorias previamente definidas e categorias sugeridas pelo próprio conteúdo no processo de análise. Esse processo foi constituído por um contínuo movimento dialógico entre os níveis empírico e teórico. Por último, buscou-se uma compreensão global do fenômeno sob estudo.

O conteúdo produzido pelo grupo focal foi utilizado para a apreensão das histórias e dos significados, sendo complementado pelo conteúdo construído nas entrevistas. Os significados foram organizados de acordo com os objetivos específicos anteriormente definidos, de modo a delinear as vivências temporais em sua tridimensionalidade, bem como os significados relativos à morte e à sua presumível aproximação.

A análise foi configurada em dois níveis, de modo análogo à proposição de Cardona e Salgado (2015). O primeiro é um nível textual, em que ocorre inclusão dos outros como parte do mundo individual e emissão de reflexões morais, estéticas e políticas, que permitem compreender o que se tem feito, sentido e pensado e as correspondentes motivações. O segundo é o nível metatextual, em que se reconfigura a trama narrativa, incluindo as interpretações anteriores e os referentes teóricos. Esse nível permite uma leitura mais macrocontextual, remetendo a aspectos socioculturais, políticos, religiosos, evidenciando como as narrativas individuais convergem entre si, articulam-se e constituem uma dimensão coletiva, compartilhada. Bruner (1991) também aponta essa tendência à 
convergência entre narrativas individuais, no sentido de que pode, complementariamente, constituir narrativas coletivas.

A apresentação das falas de cada participante será designada por um nome fictício - para assegurar a confidencialidade. Se a fala for proveniente do grupo focal, será assinalada com as letras GF; se for proveniente da entrevista, será assinalada com a letra E.

\section{Histórias e Narrativas}

\section{Passado Bifurcado}

Em relação ao passado, os participantes vivenciam dois movimentos contrários: atração e retração ou busca e evitação. Porém, não há oposição entre esses movimentos, pois são referentes a conteúdos diversos. A atração é concernente a lembranças agradáveis, da infância e da juventude.

As lembranças das traquinagens, do companheirismo, das brincadeiras antigas, que a gente, assim... era diferente. $\mathrm{Na}$ mocidade, a gente saía, passeava, ninguém tinha medo de nada. Não tinha essas maldades, essas coisas. (Marta, E) Lembro de quando eu era moça nova, das pinturas que todo jovem faz, eu me lembro! Eu lembro, assim, das coisas boas que já vivi. Da minha criancice, da mocidade, da adolescência... (Mariana, E)

E a evitação diz respeito a lembranças de sofrimento.

Mas, só lembro, hoje em dia, as coisas melhor que eu tive. As ruim eu quero é deixar pra lá. Minha vida não foi fácil.
Então, tô me sentindo melhor agora, no presente. (Mirta, GF)

O passado nos trouxe muita coisa boa. Mas, também, acho que trouxe mais ruins. As perdas que a gente teve... Quando a pessoa tá em casa, sozinha, pensa mesmo muita coisa do passado. Mas, eu tento mudar. Penso assim: oxe, e eu quero lá saber de passado?! Passado já diz tudo: passou! (Moema, GF)

Os idosos narram um passado de perdas, carências e privações, em que o aspecto socioeconômico se sobrepõe, repercutindo negativamente no campo da saúde, da educação, do trabalho e, consequentemente, da sobrevivência.

Eu digo: tempo bom é o presente, porque, antigamente, no passado, quando o idoso não podia mais trabalhar, se os filhos pudessem tomar conta dele, vivia, e, se não pudessem, ele ia pra calçada pedir esmola. Não era como no tempo de hoje, que todos os idosos se aposentam e vão criar os filhos sossegados, né? Por isso, acho que tempo bom é o presente. (Mateus, GF)

Mas tá bom hoje, porque a gente tem tudo, apesar da dificuldade. Mas tem médico, tem remédio, apesar de escasso. E, antigamente, não tinha nada disso. $\mathrm{O}$ remédio era as raízes do mato. $\mathrm{E}$, hoje, a gente vive mais tranquilo. (Mariana, GF) E eu acho assim, quando fala, hoje, em melhor idade, é melhor idade mesmo. Porque já criou os filhos... Quem já tinha sua profissão, tá em tempo ainda de 
conseguir aquilo que sonhava antes.

Porque o estudo tá aí pra quem quiser. (Márcia, GF)

Apesar disso, o passado surge como um tempo idílico marcado pela ausência da violência e da criminalidade que os idosos situam no tempo presente.

Muitas vezes, a gente lembra do passado e... assim... era mais tranquilo. Eu também morava na roça e a gente dormia até com as portas abertas. Não tinha medo de nada. E, hoje, melhorou muitas coisas, mas, muitas também ficou pior, porque a violência, tanta coisa que a gente vê, deixa a gente desassossegado. (Marta, GF)

$\mathrm{O}$ que eu acho hoje pior do que antigamente é sobre a violência, corrupção, a bandidagem. É tanto assalto, tanta coisa, que as pessoas não têm mais sossego. Se vai fazer uma viagem, já vai assombrada. (Mateus, GF) Eu acho assim: o passado foi um tempo bom, que a gente vivia tranquilo, vivia na roça, né?, na maior tranquilidade. Não tinha certos perigos. Hoje em dia, a gente vive mais sossegado numa parte. Em outra, vive assim uma vida agitada, com medo. Se tá dentro de casa, se vai pra rua, tá com medo. E aí, por uma parte é bom, por outra não é. (Mariana, GF)

Contudo, entre esses idosos, predomina uma perspectiva de apagamento do passado, de busca do esquecimento e de supervalorização do presente.
E, hoje em dia, pra quem quer estudo, tudo fica mais fácil. Só não estuda quem não quer. Por isso que eu acho que bom é o tempo de hoje. (Mateus, GF)

Eu acho o seguinte: nós temos que viver é o presente, né? Passado é passado. Diz que quem vive de passado é museu [risos]. Mas, temos que viver o presente. (Marta, GF)

E o passado, como dizem as colegas, já passou. Foi bom enquanto durou. Então, a gente tem que viver o presente pensando no futuro. (Moema, GF)

Eu, do passado, lembro raramente. Não gosto muito do passado. (Mirta, GF)

Os idosos situam o "problema" no tempo passado. Em sua percepção, o passado foi problemático. Não apenas porque significa um tempo de sofrimento, mas, também, porque se contrapõe ao que é novo. Para eles, o presente é a representação do novo. O passado, por sua vez, representa o que é velho. Como Bezerra e Lebedeff (2012) assinalam, a desqualificação da identidade na velhice é sugerida, contemporaneamente, até mesmo pelo uso da palavra "velho", que surge "[...] associada a algo retrógrado, com validade vencida, que caducou, expirou, démodé, entre outros" (p. 17).

Evidentemente, ao se apropriarem dessa noção de "velho" e rejeitarem o passado dessa forma, os idosos estão a rejeitar, simbolicamente, o próprio envelhecimento. Porém, ao supervalorizarem o presente, eles se empenham ativamente em agarrar-se ao "novo", amenizando, assim, os indícios da passagem do tempo. Rosa, Veras e Assunção (2015) nos 
chamam a atenção para o uso de determinados eufemismos, na atualidade, justamente com o intuito de suavizar a percepção do envelhecimento: terceira idade, melhor idade, idoso, espírito jovem, sênior etc. Os idosos se apropriam desses eufemismos, como podemos perceber na expressão de uma participante do presente estudo: "E eu acho assim, quando fala, hoje, em melhor idade, é melhor idade mesmo" (Márcia, GF).

\section{Presente Prometido}

$\mathrm{O}$ aspecto que leva os idosos a repudiar o passado é o mesmo que os ancora no presente, tornando-o satisfatório: as condições socioeconômicas. Agora, porém, com a polarização invertida.

Porque a gente, hoje, não tem mais dificuldade com nada. Tudo, a gente tendo o dinheiro, a gente tem como comprar... o remédio... e a gente tem como buscar um pouco a saúde, que não é tão fácil, mas, pelo menos, a gente tem como ser atendida, na saúde, na família... (Moema, GF)

Antigamente, meu Deus! A mulher ficava viúva e ia criar aqueles filhos sozinha, passando necessidade. E, hoje, só vive mal quem não tem cabeça... (Marta, GF)

A efetiva aposentadoria, com a remuneração correspondente, é a responsável por isso, na medida em que lhes possibilita a aquisição de bens e serviços antes inacessíveis. "E aí, agora tá bom, que a gente tem tudo fácil, tem o dinheirinho todo mês, tudo bom, né?!” (Mírian,
GF). "E tá bom, porque os aposentados têm seu dinheirinho" (Marta, GF).

Para os participantes do estudo, a solução está no presente, o "tempo prometido" pela aposentadoria. Para eles, atualmente, há uma valorização do idoso sem precedentes, que estimula sua participação e sua sociabilidade.

A melhor idade é essa, 60 anos, porque antigamente não tinha nada para os idosos. Ficavam lá no canto como se fossem nada. A família esquecia porque, quando casavam, cada um ia cuidar dos seus filhos e aquele pai, que cuidou, ficava no cantinho. É como se fosse uma peça velha que não servia mais para nada. E, hoje, eu vejo, principalmente os governos, eles estão preocupados em tirar esses idosos de casa e trazer assim pro meio, pro ambiente... assim... que eles conversem, né? Temos exercícios, hoje, pra fazer. (Márcia, GF)

Ao mesmo tempo, eles percebem facilitações, nos campos educacional e da saúde, que impulsionam substancialmente a vida dos menos favorecidos socialmente. Bezerra e Lebedeff (2012, p. 17) percebem “[...] na sociedade contemporânea uma preocupação exagerada com o presente e com o futuro e uma espécie de luto em relação ao passado, como um passado perdido". Podemos notar um apego exagerado ao presente, entre os idosos, mas este significa, simultaneamente, uma rejeição parcial ao passado e ao próprio envelhecimento, como afirmamos anteriormente, e uma dificuldade de situar-se numa perspectiva futura ampliada. Concordamos com Russell (2011), quando 
argumenta que a percepção de que o fim da vida se aproxima torna os idosos mais sensíveis à passagem e à vivência do tempo.

\section{Futuro Polissêmico}

Os participantes vislumbram o futuro como um tempo que se esgota, mas não se fecha. Por conseguinte, a esperança persiste, mesmo que seja apenas quanto à vida dos filhos: "No meu caso, eu penso no futuro distante para meus filhos" (Moema, GF). "O que eu faço é pedir a Deus, orar por eles [os filhos]. Porque, as outras coisas, Deus tá no controle de tudo pra operar" (Marta, GF).

O futuro é finitude e, ao mesmo tempo, abertura para a eternidade. Há, então, um futuro que finda com a morte e um futuro que avança para além dela, para além do tempo.

Na nossa idade, agora, nós temos que esquecer das coisas velhas deste mundo. Porque nós temos que buscar as coisas celestiais, chamar muito por Deus. Porque a nossa vida aqui é passageira e a de lá é eternamente. É essa que nós devemos batalhar pra alcançar, essa do futuro lá. (Marta, GF)

De todo modo, o que se impõe é um futuro que impacta e limita o projeto de vida. A presumível escassez do tempo de vida que resta reduz o horizonte da expectativa e do agir.

Não, não me arrisco a fazer planos para muitos anos, não. (Mateus, E)

Eu não faço plano pra muito tempo por causa da minha idade. Também doente, não posso nem fazer plano pra muito tempo. Se eu fizer amanhã e Deus me der tempo, eu faço amanhã. (Mariana, E)

Não faço plano, não. Pra amanhã até eu faço. Amanhã vou fazer isso assim, assim. (Marta, E)

Eu vivo um dia de cada vez. Deixo as coisas irem acontecendo. (Márcia, E)

Sendo assim, o que vemos aqui é uma perspectiva diametralmente oposta àquela que Vygotsky (1984/2000) nos permite ver, no caso das crianças que começam a vislumbrar o futuro. Diferentemente dos idosos do estudo de Russell (2011), que planejam como se fossem viver eternamente e vivem como se fossem morrer amanhã, os participantes de nosso estudo preferem não planejar ou apenas planejam e vivem como se fossem morrer depois de amanhã. Nesse sentido, os últimos são, talvez, mais pragmáticos ou menos esperançosos.

O futuro é, afinal, uma incógnita.

Diz que a gente tem que pensar no dia de hoje, porque o amanhã não nos pertence... (Marta, E)

Então, a gente tem que viver o presente pensando no futuro. Porque também a gente não pode esquecer que o futuro pertence a Deus, mas a gente tem que pensar como poderá ser. (Moema, GF)

O futuro é, sobretudo, polissêmico. Há um futuro desconhecido e um futuro possível, que insiste em se tornar cada vez mais próximo. Para o segundo, algum planejamento parece ser visto como necessário. Para Rendell et al. (2012), as dificuldades dos idosos em projetar episódios futuros são relacionadas a lacunas na imaginação, 
ampliadas quando a consciência autonoética é requerida. Uma redução no funcionamento do hipocampo seria a base do problema. Porém, do nosso ponto de vista, a narrativa dos idosos aponta outra possibilidade, que não contradiz necessariamente os autores citados, mas propicia uma compreensão mais simples ou, até mesmo, complementar àquela: o que dificulta imaginar-se no futuro é a percepção, e o consequente receio, de que o tempo é cada vez mais exíguo para esperar que a realização se efetive. Concordamos com Berger e Luckmann (2011), quando afirmam que a atitude quanto à realização é que é afetada.

\section{Entre o Futuro e a Morte: a Metáfora}

A experiência da morte e do morrer surge como metáfora. É um tema espinhoso, delicado, que mobiliza afetos inquietantes, conhecimentos e desconhecimentos.

1. A morte como retorno à terra natal: " $\mathrm{E}$, do meu futuro, o que eu mais quero é voltar pra morrer na minha terra. Antes de morrer, quero voltar pra minha terra" (Mateus, GF).

2. A morte como solidão e desespero: "Porque eu fico pensando: eu morro de medo de quem morre. E eu fico pensando, às vezes, eu vou morrer $\mathrm{e}$ vão me levar e me deixar lá no cemitério. Aí, todo mundo vai embora e me deixa lá sozinha. E, naquele escuro, eu vou ficar só. Fico pensando essas coisas da morte" (Márcia, GF).

3. A morte como continuidade do presente: "O fim do meu tempo imagino assim: se for como estou hoje, contente, alegre, dançando, com essa coragem toda, se Deus me ajudar, pra mim vai ser ótimo! Se Deus me der mais uns anos de vida..." (Mariana, GF).

4. A morte como travessia: "Ninguém pense que a morte é facilzinha assim, que não é, não, viu?! Eu até meditava naquele salmo: o Senhor é meu pastor e nada me faltará. Porque, olhe, atravessar o vale não é fácil, não!” (Marta, GF).

Em seu estudo, Menezes e Lopes (2014) entenderam que a rejeição à proximidade da morte significa, entre os idosos, a rejeição à velhice. No presente estudo, porém, podemos notar que essa rejeição à velhice é mais complexa e remete, também, às memórias do passado e às vivências do presente. Diz respeito tanto ao sofrimento do passado quanto ao apego ao presente e ao receio do futuro. Isso quer dizer que as três dimensões temporais concorrem, simultaneamente, para compor as vivências e a identidade do idoso.

\section{Êxodo Temporal: a Travessia}

As narrativas dos idosos convergem para a constituição de uma epopeia geracional, marcada, em sua origem, pela precariedade econômica, pela vulnerabilidade social e pelo sofrimento. O desenvolvimento desse formato narrativo sugere uma espécie de desenraizamento parcial do passado, forçado pelas condições adversas vividas, e uma ancoragem no tempo presente, tempo prometido pela esperança na aposentadoria, a partir do qual se torna possível uma avaliação retrospectiva da trajetória. Essa epopeia ganha as feições de um êxodo, ocorrido por meio de uma longa peregrinação no tempo. Os idosos parecem fugitivos do passado e com 
ele mantêm uma relação ambígua, misto de saudade e ostensiva desqualificação.

Bezerra e Lebedeff (2012, p. 17) referemse a uma "sensação de deslocamento temporal", que seria um "estar fora do tempo" experimentado pelo idoso, por se sentir à margem da coletividade. Entretanto, na narrativa dos participantes do presente estudo, a percepção de ser excluído remete ao passado. O presente significa a conquista da superação.

O êxodo tem ponto de partida, um caminho pontilhado por dificuldades, perdas e ganhos, a conquista do presente e um ponto de seguimento. Esse seguimento, embora seja orientado pela esperança, tem adiante uma barreira, não se sabe quando, que pode significar o fim ou exigir mais uma difícil travessia.

As dificuldades dizem respeito, por exemplo, ao constante esforço para não lembrar, para não deixar que as memórias do passado venham à tona.

Quando a pessoa tá em casa, sozinha, pensa mesmo muita coisa do passado. Mas, eu tento mudar. Penso assim: oxe, e eu quero lá saber de passado?! Passado já diz tudo: passou! É melhor a gente pensar no presente, né? $\mathrm{E}$ pensar as coisas boas para o futuro. O passado traz marcas, não é? Mas, a gente tem que apagar. Tentar esquecer. O que passou, passou. (Moema, GF)

Quando tô em casa sozinha, nem penso no passado. Quase só vivo sozinha. Faço uma coisa, faço outra... Mas, pra ficar sentada, lembrando do passado, aquelas coisas, eu não! (Marta, GF)
Eu não posso nem pensar. Vou dizer por quê. Se eu pensar, fico nervosa. Se estou sozinha, fico fazendo crochê. Então, fico pensando só naquilo, se não eu erro. Se mudar o sentido do que tô fazendo, eu erro. (Mariana, E)

Às vezes, a saudade incomoda um pouco. Mas, quando a lembrança vem, começo a fazer outras coisas e não deixo ficar muito tempo. (Márcia, E)

Como estratégia para evitar que lembranças incômodas inundem a consciência, os idosos se empenham na realização de atividades práticas, que exijam intensa concentração da atenção. Consideramos pertinente a consideração de Russell (2011) de que os idosos priorizam atividades que sejam mais significativas para eles e não apenas escolhem muitas atividades para manterem-se ocupados. Entretanto, enfatizamos que as duas perspectivas são igualmente razoáveis. Os idosos parecem atribuir múltiplos significados a essas atividades: significados laborais, artísticos, estéticos, de passatempo etc. Porém, quando se sentem acossados por memórias incômodas, essas atividades tornam-se úteis, principalmente, como estratégia para mudar o foco de atenção.

Contudo, quando a atividade é significativa, os idosos não se importam se lhes toma todo o tempo do dia (Russell, 2011). Isso fica bem claro na seguinte resposta: "O que mais gosto de fazer, não é? Artesanato. Fico, às vezes, se me deixarem, o dia inteiro no meu ateliezinho, que não lembro nem de comer. Gosto muito. Também gosto muito de ler. Gosto de ler a Bíblia. Qualquer livro que caia na minha mão" (Márcia, E). 
Dizíamos, anteriormente, que o êxodo temporal implica, também, em perdas. Estas são de vários tipos. Há a perda de entes queridos: "Ih, é difícil me emocionar! É assim, saudade a gente sempre sente, não é? Pessoas que já passaram na vida da gente...” (Moema, E).

Há a perda de competências físicas e psicológicas e de experiências de prazer: "Assim... de relação sexual, que a gente tinha antes e, hoje, devido à idade, não tem mais. Aí, sente muita falta" (Mateus, E).

Ou, ainda: "Só tem uma coisa do passado que eu sou medonha pra lembrar, que é de comida! Porque, no passado, a gente tinha pouca coisa, mas tinha comida, que era gostosa! Carne assada... Porque hoje tem tudo, mas a gente nem pode comer, porque tudo faz mal, né?" (Marta, GF).

Talvez, uma das perdas mais severas nesse processo de envelhecimento seja relativa à memória. Invariavelmente, refere-se a acontecimentos recentes do cotidiano vivido.

Tenho, esquecimento tem um pouquinho com essa idade. Sempre tem um esquecimento. Coisa do presente é mais fácil. Coisa do passado esqueço menos do que coisa do presente. Tudo que me aconteceu na infância eu tenho na memória. (Mateus, E)

Eu sei que esqueço muito das coisas... Mais recentes. De hoje, de ontem. (Mariana, E)

Eu esqueço, assim, às vezes, do nome da pessoa. Mas ainda aprendo a fazer as coisas, ainda decoro as coisas. Lembro mais das coisas antigas. Às vezes, de coisas recentes. Se eu ficar pensando naquele negócio, eu não esqueço, não. Mas se eu não ligar... (Marta, E)

Das pequenas coisas. Às vezes, eu vou cozinhar e esqueço o tempero. Às vezes, esqueço a porta da geladeira aberta... $\mathrm{O}$ fogo ligado, a panela de pressão no fogo... Mais ou menos assim (Márcia, E)

Segundo Mandler (citado por Bruner, 2002), a memória perde conteúdos que não são estruturados narrativamente. A narrativa dos idosos parece condizente com essa compreensão, por se referir a esquecimentos de ações comuns do cotidiano, que, por não se afastarem de padrões culturais canônicos, não ensejam a construção de histórias antes da ocorrência efetiva do esquecimento.

As histórias contadas pelos participantes deste estudo são, não raro, marcadas por referências religiosas cristãs. Estas aparecem na forma de agradecimento, de súplica, de expectativa, de submissão etc.

Penso assim, que Jesus me ajude a me aposentar... (Madalena, GF)

Fico pensando essas coisas da morte. Leio muito a Bíblia, mas... Tenho que me chegar mais a Deus e superar isso, vencer essa barreira. Acho que vou conseguir. (Márcia, GF)

Se Deus me der mais uns anos de vida... (Mariana, GF)

Porque eu penso assim: quando eu "tava com meus filhos, pedia a Deus pra dar um jeito de eu criar meus filhos, educar meus filhos" (Mateus, E)

Até hoje eu agradeço a Deus. Porque a gente ficar sem marido... Já tem 38 anos. 
E criei todos os seis, graças a Deus! (Moema, E)

Então eu disse a Deus: se for minha hora, me leve logo, mas se eu tiver ainda alguma missão, faça de mim uma pessoa melhor. (Marta, GF)

Vieira (2009) e Mello (2012) evidenciam a importância que a dimensão da espiritualidade ganha no processo de envelhecer, seja para significar o propósito da vida, seja para robustecer a resiliência na condução da última etapa dessa jornada. À dimensão espiritual soma-se um ganho essencial para a velhice: a sabedoria. Segundo Randall (2013), a pessoa é sábia quando está apta a ver a vida como uma história evolutiva e criar alguma distância entre si mesma e a história, refletindo sobre ela de múltiplas perspectivas.

Vou completar 82 anos, mas no futuro ainda penso. Porque sou analfabeto, mas, depois dos 81 anos, fiz um livro sobre o entendimento de um analfabeto, com 152 páginas. E já vendeu trezentos livros e todo mundo que já leu gostou e tá me cobrando: e vai fazer o segundo? (Mateus, GF)

Então, a gente tem que viver o presente pensando no futuro. Porque também a gente não pode esquecer que o futuro pertence a Deus, mas a gente tem que pensar como poderá ser. Mesmo que não seja aquilo que a gente tanto espera, mas a gente deve pensar. (Moema, GF)

$\mathrm{Na}$ nossa idade, agora, nós temos que esquecer das coisas velhas deste mundo. Porque nós temos que buscar as coisas celestiais, chamar muito por Deus.
Porque a nossa vida aqui é passageira e a de lá é eternamente. (Marta, GF)

E eu creio que se Deus me deu mais uns dias, eu pedi pra ser uma pessoa melhor, com os meus filhos, com os amigos, amar mais ao próximo, porque essa vida requer um pouco mais de santidade e de humildade. (Marta, GF)

Compreendemos que o contraponto entre o declínio das competências físicas e o avanço para a autotranscendência é o que constitui a grande e produtiva contradição do envelhecer. Isso talvez seja, justamente, a abertura que alça o ser humano ao ápice do seu desenvolvimento individual: a sabedoria.

Sendo assim, podemos perceber que quando opta pelo adulto como modelo para o desenvolvimento da criança, como Vygotsky (1984/2000) havia notado, a cultura que é orientada, contemporaneamente, pelos ditames capitalistas trata de encaminhá-la para modos de "ser produtiva"; e quando opta por tomar a juventude como modelo ideal, como observam Kehl (2004) e Ribeiro (2004), essa cultura prioriza modos de ser calcados na superficialidade e na aparência. Diferentemente da cultura Guarani e Kaiowá (Benites, 2014) e da comunidade quilombola (Santos \& Chaves, 2007), na sociedade capitalista atual predomina uma cultura que descarta tanto as pessoas idosas quanto a sua sabedoria. Como consequência, ganhamos uma grande lacuna no processo de humanização das novas gerações.

\section{Considerações Finais}

No caso dos idosos que nos permitiram o presente estudo, pudemos notar, numa 
apreciação panorâmica, que ao relatarem suas histórias sobre como vivenciam o tempo, estas convergiram para configurar um gênero narrativo. Trata-se de uma verdadeira epopeia, ainda que em prosa, num formato muito similar ao êxodo bíblico, mas que se desenvolve entre as três conhecidas dimensões do tempo. Essa narrativa nos revela, portanto, uma epopeia temporal, evoluindo em sua dramaticidade desde um passado de vulnerabilidade social até um presente visto como tábua da salvação ou tempo prometido. Tempo prometido pela conquista da aposentadoria, que surge como acontecimento crucial para concretizar anseios básicos dessas pessoas por uma vida mais digna.

Agarrando-se ao tempo presente como signo do "novo", os idosos tentam amenizar a percepção do próprio processo de envelhecimento, ao mesmo tempo em que se veem diante de outro desafio, talvez ainda mais magnífico: mover-se do presente para o futuro. Um futuro que é anúncio do fim da vida ou do início de uma nova travessia para além do tempo.

Nessa dupla transição temporal, marcada por sofrimentos e superações e, sobretudo, por inumeráveis e presumíveis aprendizagens, os idosos, enquanto perdem competências físicas e experiências de prazer correlatas, alcançam o topo de sua trajetória desenvolvimental. Estar no topo significa, por conseguinte, vislumbrar a vida como uma grande história, da qual é possível derivar ensinamentos compartilháveis, que por outros podem ser reconhecidos ou não como sabedoria.

Ao construirmos a presente narrativa, como resultado de um processo investigativo, sabemos que apresentamos apenas uma interpretação possível das interpretações que esses idosos se disponibilizaram a construir, generosamente, enquanto interagíamos. Outras interpretações serão sempre possíveis. Deste processo investigativo saem e ganham corpo algumas provocações para futuros empreendimentos investigativos. Por exemplo: A intenção consciente de esquecer aspectos do passado pode contribuir para que os idosos apresentem lacunas ou dificuldades, ao projetar realizações futuras? Ou os receios relativos à finitude da vida já são suficientes para isso? Esses receios podem ser reduzidos pela ampliação da autotranscendência?

Os participantes do estudo vivenciam as dimensões do tempo de maneiras singulares e, ao mesmo tempo, coletivamente convergentes. Essas vivências repercutem na forma como se posicionam em relação à vida e à morte e viceversa. Ao fim e ao cabo, tudo parece depender de como se chega ao topo da trajetória desenvolvimental, do alcance da autotranscendência e da atribuição de sentidos à vida como uma totalidade.

\section{Referências}

Adami, F., Frainer, D. E. S., Santos, J. S., Fernandes, T. C., \& De-Oliveira, F. R. (2008). Insatisfação corporal e atividade física em adolescentes da região continental de Florianópolis. Psicologia: Teoria e Pesquisa, 24(2), 143-149.

Benites, T. (2014, março). A educação dos jovens Guarani e Kaiowá e sua utilização das redes sociais na luta por direitos. Desidades, 2(2), 9-17.

Berger, P. L., \& Luckmann, T. (2011). A construção social da realidade: tratado de sociologia do 
conhecimento (33a ed., F. de S. Fernandes, Trad.). Petrópolis: Vozes.

Bezerra, D. B., \& Lebedeff, T. B. (2012). Inscrições no tempo e identidade: o idoso na sociedade ocidental contemporânea, vínculo com o futuro ou estigma de finitude?. Cadernos do LEPAARQ-Textos de Antropologia, Arqueologia e Patrimônio, 9(17/18), 27-47.

Brasil. (1995). Estatuto da criança e do adolescente: Lei no 8069, de 13 de julho de 1990 (5a ed.). São Paulo: Peres.

Brasil. (2003). Estatuto do Idoso: Lei $n^{\circ} 10.741$, de $1^{\circ}$ de outubro de 2003. Brasília, DF: Presidência da República. Recuperado em 17 maio, 2017, de http://www.planalto.gov.br/ccivil_03/ LEIS/2003/L10.741.htm

Bruner, J. (1991). The narrative construction of reality. Critical Inquiry, 18(1), 1-21.

Bruner, J. (2002). Atos de significação (S. Costa, Trad.). Porto Alegre: Artes Médicas.

Camarano, A. A., Mello, J. L., \& Kanso, S. (2006). Do nascimento à morte: principais transições. In A. A. Camarano (Org.). Transição para a vida adulta ou vida adulta em transição? (pp. 31-60). Rio de Janeiro: Ipea.

Cardona, A. M. A., \& Salgado, S. V. A. (2015, julio/diciembre). Investigación narrativa: apuesta metodológica para la construcción social de conocimientos científicos. Revista CES Psicología, 8(2), 171-181.

De la Ossa, E. D., \& González, J. D. H. (2013, septiembre/diciembre). La investigación narrativa en Psicología: definición y funciones. Psicología desde el Caribe, 30(3), 620-641.

Erikson, E. (1998). O ciclo de vida completo. Porto Alegre: Artmed.

Freud, S. (1973a). Tres ensayos para una teoria sexual. In S. Freud, Obras completas (3a ed., vol. 2, pp. 1169-1230, L. LopezBallesteros \& De Torres, Trad.). Madrid: Biblioteca Nueva. (Trabalho original publicado em 1905).

Freud, S. (1973b). Teoría general de las neurosis. In S. Freud, Obras completas (3a ed., vol. 2, pp. 2311-2333, L. Lopez-Ballesteros \& De Torres, Trad.). Madrid: Biblioteca Nueva. (Trabalho original publicado em 1916-7).

Kehl, M. R. (2004). A juventude como sintoma da cultura. In R. Novaes \& P. Vannuchi (Orgs.). Juventude e sociedade: trabalho, educação, cultura e participação (pp. 89-114). São Paulo: Fundação Perseu Abramo.

Madeira, F. R. (2006). Educação e desigualdade no tempo de juventude. In A. A. Camarano (Org.). Transição para a vida adulta ou vida adulta em transição? (pp. 139169). Rio de Janeiro: Ipea.

Martins, E., \& Szymanski, H. (2004, $1^{\text {o }}$ semestre). A abordagem ecológica de Urie Bronfenbrenner em estudos com famílias. Estudos e Pesquisas em Psicologia, 4(1), 63-77.

Mello, M. A. (2012). Velhice e espiritualidade na perspectiva da psicologia analítica. Tese de doutorado, Pontifícia Universidade Católica de São Paulo, São Paulo.

Menezes, T. M. de O., \& Lopes, R. L. M. (2014). Ciência \&o Saúde Coletiva, 19(8), 33093316. 
Piaget, J. (1999). Seis estudos de Psicologia (24a ed.).

Rio de Janeiro: Forense Universitária.

Randall, W. L. (2013). Aging, Irony, and Wisdom: on the Narrative Psychology of Later Life. Theory and Psychology, 23(2), 164-183.

Rendell, P. G., Henry, J. D., Gaskin, S., Bailey, P. E., Phillips, L. H., \& Kliegel, M. (2012). Older Adults Have Greater Difficulty Imagining Future Rather than Atemporal Experiences. Psychology and Aging, 27(4), 1089-1098.

Ribeiro, R. J. (2004). Política e juventude: o que fica da energia. In R. Novaes \& P. Vannuchi (Orgs.). Juventude e sociedade: trabalho, educação, cultura e participação (pp. 19-33). São Paulo: Fundação Perseu Abramo.

Rosa, C. M., Veras, L., \& Assunção, A. (2015). Reflexos do tempo: uma reflexão sobre o envelhecimento nos dias de hoje. Estudos e pesquisas em Psicologia, 15(3), 1027-1044.

Russell, H. (2011, November). Time and Meaning in Later-Life Learning. Australian Journal of Adult Learning, 52(3), 547-565.

Santos, G. L., \& Chaves, A. M. (2007, julho/setembro). Ser quilombola: representações sociais de habitantes de uma comunidade negra. Estudos de Psicologia, 24(3), 353-361.

Schneider, R. H., \& Irigaray, T. Q. (2008, outubro/dezembro). O envelhecimento na atualidade: aspectos cronológicos, biológicos, psicológicos e sociais. Estudos de Psicologia, 25(4), 585-593.

Traverso-Yépez, M. A., \& Pinheiro, V. de S. (2002, julho/dezembro). Adolescência, saúde e contexto social: esclarecendo práticas. Psicologia \& Sociedade, 14(2), 133147.

Vieira, M. G. de O. (2009). Velhice e espiritualidade: reflexões sobre as transformaçôes do envelhecer. Dissertação de mestrado, Universidade de Brasília, Brasília.

Vygotsky, L. S. (2000). A formação social da mente (6a ed.). São Paulo: Martins Fontes. (Trabalho original publicado em 1984).

Recebido em: 18/06/2017 Aprovado em: 08/02/2018 